\title{
Thrombotic Obstruction of the Right Coronary Artery in a Postoperative Patient with Bland-White-Garland Syndrome
}

\author{
Junichi Ejıma, M.D., Mika Fujrmoto, M.D., \\ Toru Maruyama, M.D., Yoshikazu KaJi, M.D., \\ Yasuo Tsuda, M.D., Takeshi OHTSUKa, M.D., \\ Shozo KanaYa, M.D., ${ }^{*}$ Takehiko Fujino, M.D.,* \\ and Yoshiyuki NıHO, M.D.
}

\section{Summary}

A 53-year-old female presented with symptoms of severe chest and back pain associated with oliguria. The patient had a history of exertional dyspnea since the age of 20 , and easy fatigability since the age of 27 . At the age of 41 , she noted marked exacerbation of these symptoms after suffering from a cold and was ultimately diagnosed as having Bland-White-Garland (BWG) syndrome with mitral valve regurgitation. The patient then underwent re-implantation of an anomalous left coronary artery from the pulmonary artery to the posterolateral wall of the aorta. Eleven years later, she re-presented with symptoms of angina and congestive heart failure. Coronary angiography was subsequently performed and a total occlusion of the right coronary artery with probable thrombus was revealed. The right coronary artery was filled via collaterals from the implanted left coronary artery. Mitral regurgitation was noted during angiography. The patient underwent aorto-coronary artery bypass grafting of the right coronary artery and concomitant mitral valve replacement. Her postoperative condition remained excellent. (Jpn Heart J 35: 87-94, 1994)

Key words: Bland-White-Garland syndrome Thrombotic obstruction Right coronary artery Postoperative

R LAND-WHITE-GARLAND syndrome (BWG), is a rare disease that is D associated with premature myocardial ischemia, early mortality (prior to the age of one year), and an anomalous origin of the left coronary artery. ${ }^{1,2)}$ Ligation of the coronary artery at its origin within the pulmonary artery as a means of palliation has been a controversial mode of therapy. ${ }^{3)}$ Recently, however, improved surgical methods have been described.

From the First Department of Internal Medicine, Faculty of Medicine, and *Institute of Health Science, Kyushu University, Fukuoka, Japan.

Address for correspondence: Junichi Ejima, M.D., Ishihara Hospital, Komonto-chou 1-2, Hakata-ku, Fukuoka 812, Japan.

Received for publication July 19, 1993.

Accepted November 12, 1993. 
We report a case of a patient with BWG syndrome in which an anomalous left coronary artery arising from the pulmonary artery was re-implanted onto the posterolateral wall of the aorta. Obstruction of the right coronary artery due to thrombosis occurred 11 years after surgery.

\section{Case Report}

The patient was a 53-year-old female who presented with a chief complaint of chest pain. She had no history of prior rheumatic fever or Kawasaki's disease. Between the ages of 26 and 32, the patient had given birth to four children without any complications.

Symptoms of exertional dyspnea, however, were first noted at age 20 and progressed to easy fatigability by age 27. During hospitalization for pneumonia and anemia at the age of 29 , electrocardiographic abnormalities were noted. At the age of 32, the patient was re-hospitalized for progressive dyspnea, orthopnea and edema and was treated for congestive heart failure for approximately 40 days.

When she was 41 , she experienced severe exertional dyspnea and easy fatigability after suffering from a cold.

Cardiac catheterization done at our institution at that time revealed evidence of BWG syndrome. Implantation of an anomalous lcft coronary artery from the pulmonary artery to the posterolateral wall of the aorta was performed. The patient's symptoms disappeared postoperatively.

She was re-admitted two years later for follow-up. Repeat coronary angiography revealed normal circulation within the left and right coronary arteries and the grade of mitral valve regurgitation was not markedly changed.

The patient did well until the development of nocturnal chest pain at the age of 52. Her chest pain was anteriorly located, lasted 2-3 minutes, and was relieved by sublingual administration of isosorbide dinitrate. She also noted prolonged episodes of back pain and a significant decrease in urination. Roentgenographic examination revealed development of cardiomegaly and she was subsequently admitted to our hospital.

At the time of admission, the patient measured $154 \mathrm{~cm}$, and weighed $58 \mathrm{~kg}$. Vital signs revealed an irregular pulse rate of $84 / \mathrm{min}$, and a blood pressure of 112/64 mmHg. Physical examination revealed jugular venous distention and a III/VI holosystolic apical murmur. Breathing was labored and moist rales were noted over the right middle and lower lung fields. The liver was palpable threefinger breadths below the costal margin. Pretibial edema was observed.

On admission, laboratory examination revealed normal leukocyte and CPK levels. There was no evidence of altered coagulation and platelet counts were 

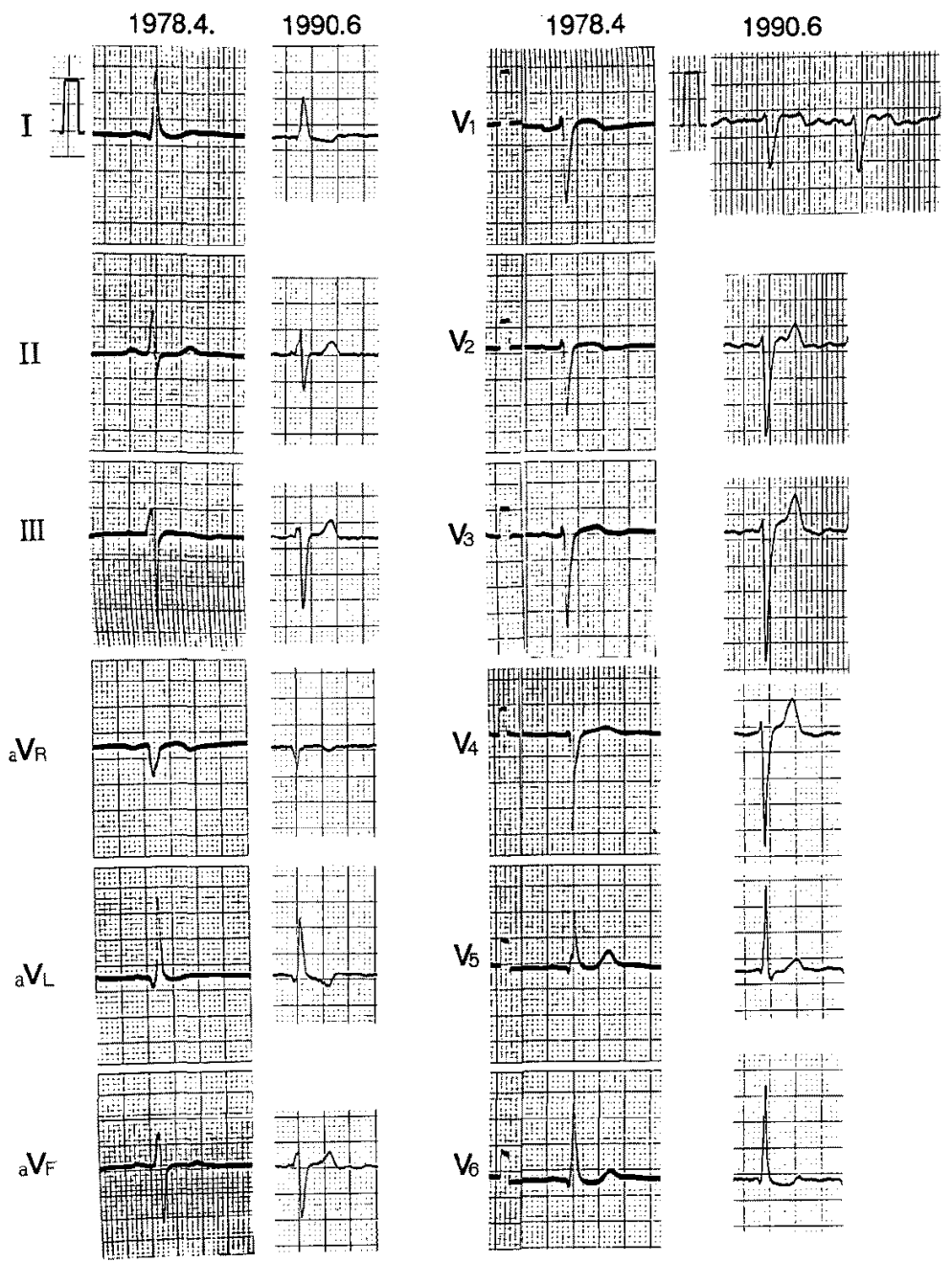

M.Y. F

Figure 1. Electrocardiogram (ECG) demonstrates fibrillation, left axis deviation, poor $R$ progression from leads $V_{1}$ to $V_{t}$, and negative $T$ waves in leads $I$ and $a V_{L}$. Compared with the ECG taken at the age of 41 , no changes were noted with the exception of atrial fibrillation.

within normal limits.

The electrocardiogram demonstrated atrial fibrillation, left axis deviation, poor $\mathrm{R}$ progression, and inverted $\mathrm{T}$ waves in leads $\mathrm{I}$ and $\mathrm{a} \mathrm{V}_{\mathrm{L}}$. With the exception of the development of atrial fibrillation, these electrocardiographic changes had been previously noted (Figure 1).

A chest roentgenogram revealed a cardiothoracic ratio of $58.5 \%$, and slightly prominent pulmonary vasculature.

Previous coronary angiography performed pre-operatively had revealed 


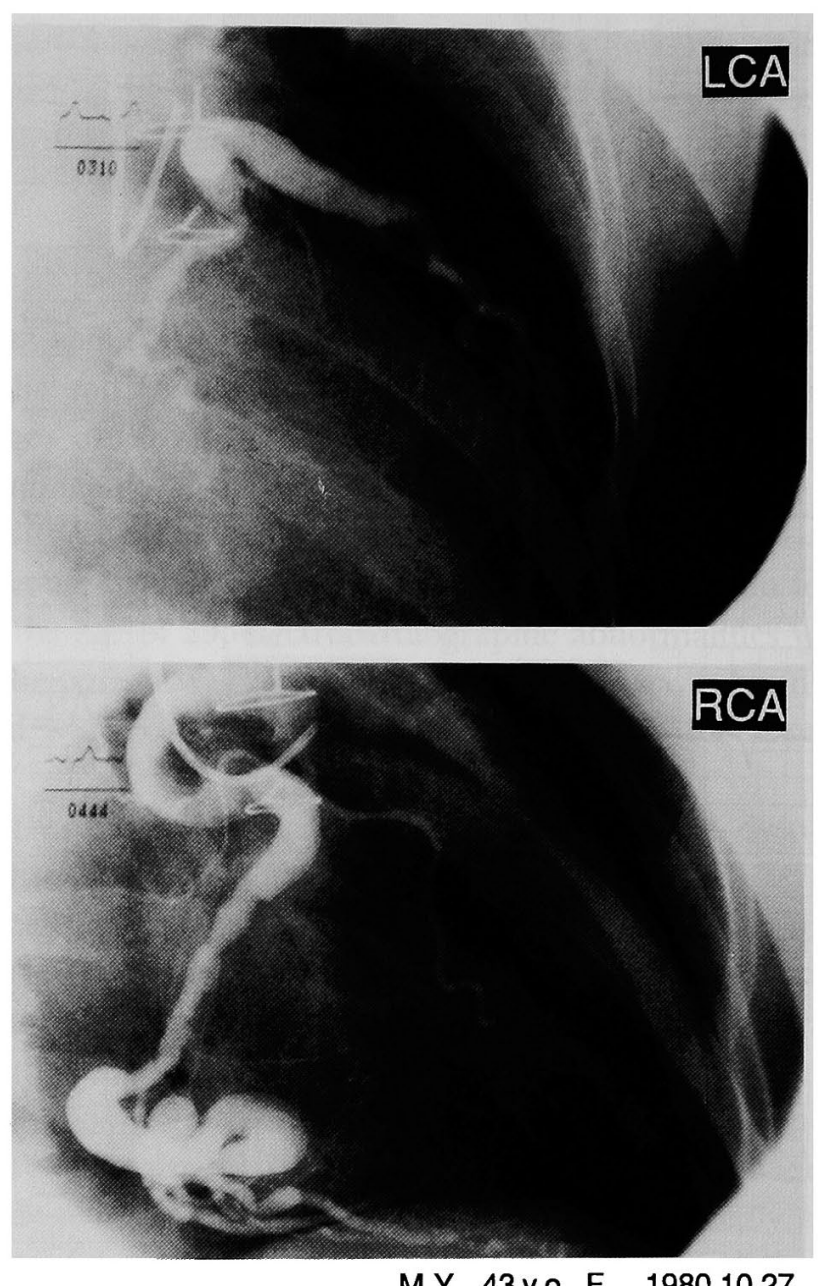

M.Y. 43 y.o. F 1980.10 .27

Figure 2. Coronary angiography performed two years after surgery revealed a normal circulation within the left and right coronary arteries.

that the origin of the left coronary artery was the left pulmonary artery, and that there were significant collaterals from the right coronary artery to the left coronary artery. Both right and left coronary arteries were markedly dilated and tortuous. Although hemodynamic measurements were within normal limits, a distinct oxygen step-up was detected in the left pulmonary artery. Coronary angiography performed 2 years postoperatively revealed satisfactory circulation within the left and right coronary arteries (Figure 2). A left ventriculogram showed hypokinesis of segments (2) and (3) and grade II mitral valve regurgitation. 

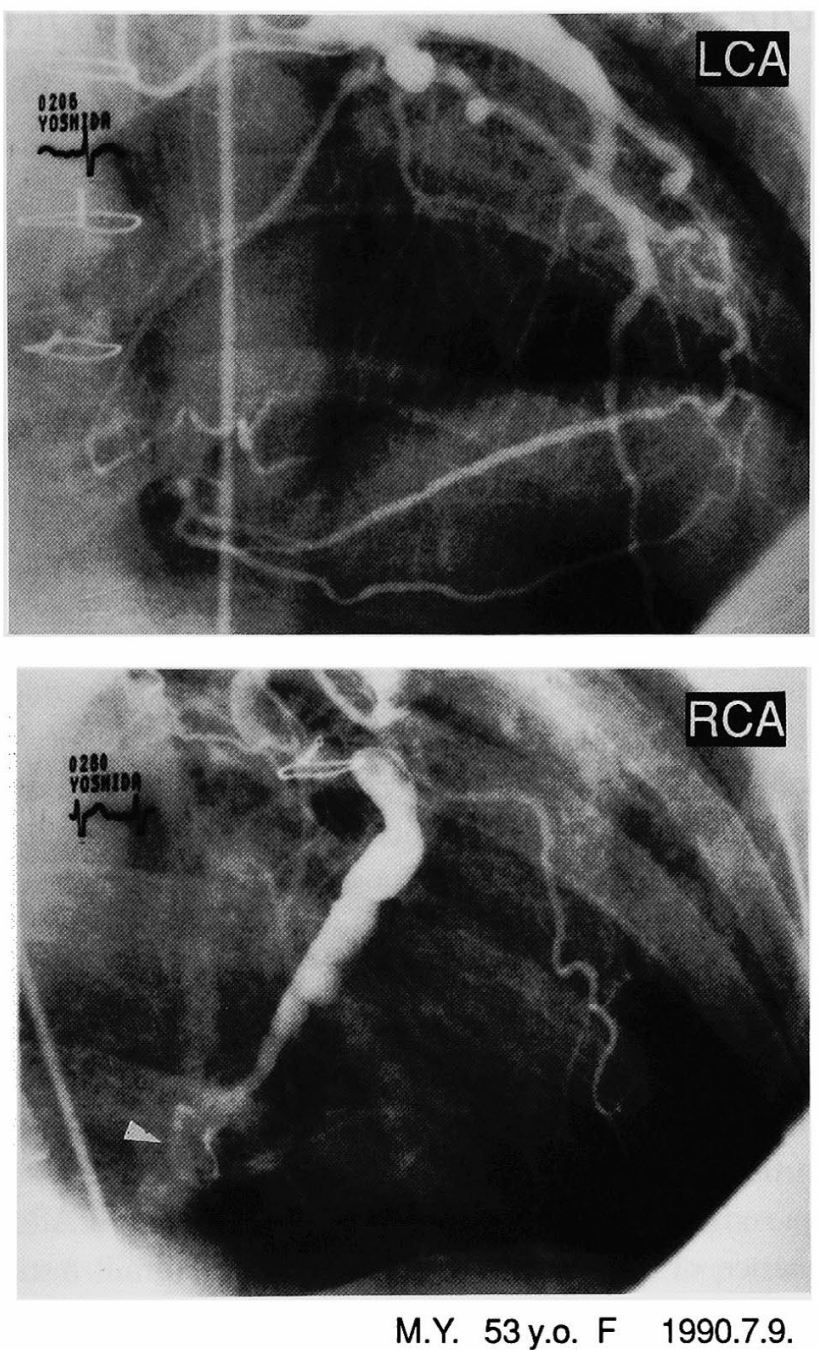

Figure 3. Coronary angiography performed 11 years after surgery demonstrated a $100 \%$ obstruction in segment 3 of the right coronary artery probably secondary to thrombus formation. While no distinct changes were observed in the left coronary artery, collateral blood flow is seen from left to right coronary arteries.

Repeat coronary angiography done nine years later revealed a total occlusion of the right coronary artery, most likely induced by thrombus. However, no changes were observed with respect to collateral blood flow from the left coronary artery to the right coronary artery (Figure 3). Left ventriculography demonstrated grade III mitral valve regurgitation (Figure 4). Hemodynamic measurements revealed a mean pulmonary arterial wedge pressure of $16 \mathrm{mmHg}$, a mean 

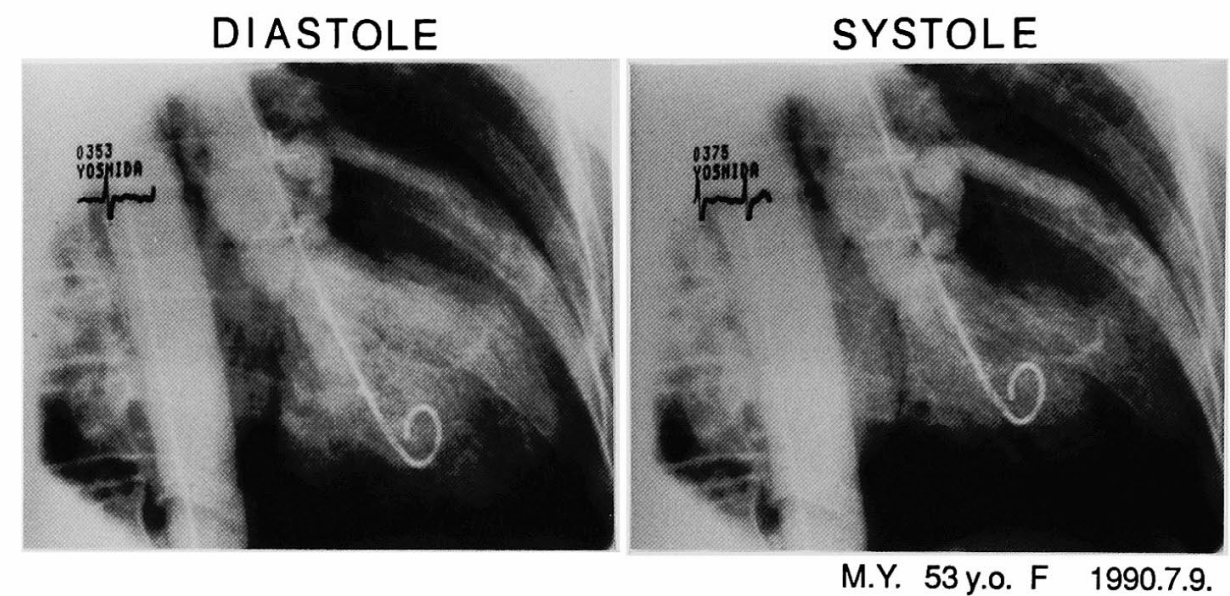

Figure 4. Left ventriculography done 11 years after surgery demonstrates grade III mitral valve regurgitation.

pulmonary arterial pressure of $22 \mathrm{mmHg}$, a right ventricular diastolic pressure of $11 \mathrm{mmHg}$, and an elevated left ventricular diastolic pressure of $13 \mathrm{mmHg}$. The left ventricular diastolic volume was $125 \mathrm{ml}$, the left ventricular systolic volume was $60 \mathrm{ml}$ and the left ventricular ejection fraction was $52 \%$. Myocardial scintigraphy revealed perfusion defects within the anteroseptal wall and inferior wall.

Thus, the etiology of heart failure in our patient appeared to be mitral regurgitation and angina pectoris. A regimen of vasodilator, diuretic, and anticoagulation therapy was therefore instituted and led to the disappearance of symptoms and a reduction in the cardiothoracic ratio to $55 \%$. After achieving 6.5 mets in the absence of symptoms during exercise treadmill testing, the patient was discharged from the hospital. However, she experienced symptoms of heart failure once a month after discharge and ultimately underwent aorto-coronary artery bypass grafting to the RCA and mitral valve replacement.

\section{Discussion}

Surgical treatment for BWG syndrome, a rare congenital cardiac anomaly, has been changing as understanding of the disease process becomes clearer. Currently there seems to be little controversy regarding the establishment of a two-coronary flow system by reconstruction of the anomalous left coronary artery from the pulmonary artery. ${ }^{4-6)}$ In 1966, Likar, et al ${ }^{77}$ evaluated the surgical results of 11 simple cases involving ligation, and reported that optimal results were obtained by performing coronary revascularization and establishing a two-coro- 
nary flow system by constructing an atriovenous fistula and a systemic-to-left coronary artery anastomosis instead of simple ligation of the anomalous left coronary artery. Furthermore, the authors suggested that the most logical surgical approach was aortic implantation of the anomalous left coronary artery."

In the absence of surgical repair, the natural prognosis of the disease is extremely poor and the majority of patients die within a few months of birth. However, there is a paucity of data available regarding the optimal revascularization procedure in such young patients. ${ }^{2,8,9)}$

Our patient had no risk factors for ischemic heart disease and no evidence of Kawasaki's disease. Additionally, therc was no suggestion of coagulation abnormalities. Both right and left coronary arteries demonstrated marked tortuousity and dilatation. Initially, there were significant collaterals from the right coronary to the left coronary artery. After the establishment of a two coronary flow system, the flow in the right coronary artery was reduced.

The tortuous and dilated nature of the artery, together with a reduction in flow, most likely led to flow stasis and predisposition to thrombus formation. This raises an additional hazard of converting a single coronary flow system to a double system. Moreover, exercise performance may not be affected by the age at which the patient is operated upon as our patient achieved 6.5 mets on the treadmill 11 years after surgical repair. This may result in delayed diagnosis of right coronary arterial obstruction. ${ }^{10)}$

In the BWG syndrome, fibrosis of the left ventricular papillary muscle occurs and leads to papillary insufficiency and mitral regurgitation. After revascularization, papillary muscle function is expected to recover. To assess the relationship between left ventricular function, the mitral apparatus, and mitral regurgitation, Yoran, et al conducted experimental studies with epinephrine loading and noted that increased left ventricular contractility decreases the reflux area and results in reduced mitral valve regurgitation. ${ }^{11}$ However, in our patient, left ventricular function did not change after surgery. Subsequently, mitral valve replacement and coronary bypass grafting were performed due to heart failure. Since valve replacement and coronary bypass grafting, there has been no recurrence of heart failure.

Our case demonstrates some of the problems in the evaluation and surgical treatment of patients with BWG syndrome and mitral regurgitation.

\section{References}

1. Bland EF, White PD, Garland J: Congenital anomalies of the coronary arteries; report of an unusual case associated with cardiac hypertrophy. Am Heart J 8: 787, 1933

2. Wesselhoeff H, Faucett JS, Johnson AL: Anomalous origin of the left coronary artery from the pulmonary trunk; its spectrum, pathology, and pathophysiology, based on a review of 140 cases with seven 
further cases. Circulation 38: 403, 1968

3. Tanimoto X, Endoh M, Konno S: Surgical treatment of Bland-White-Garland syndrome; the problem of ligation of the anomalous coronary artery. Heart 6: 1299, 1974 (in Japanese)

4. Moodie DS, Fyfe D, Gill CC, Cook SA, Lytle BW, Fitzgerald CTR, Sheldon WC: Anomalous origin of the left coronary artery from the pulmonary artery (Bland-White-Garland syndrome) in adult patients; long term follow up after surgery. Am Heart J 106: 381, 1983.

5. Takeuchi S, Imamura H, Katsumoto J, Hayashi I, Katohgi T, Yada R, Ohkura M, Inoue T: New surgical method for repair of anomalous left coronary artery from the pulmonary artery. $J$ Thorac Cardiovasc Surg 78: 7, 1979

6. Wilson CL, Dlabal PW, McGuire SA: Surgical treatment of anomalous left coronary artery from pulmonary artery; follow-up in teenagers and adults. Am Heart J 98: 440, 1979

7. Likar I, Criley JM, Lewis KB: Anomalous left coronary artery arising from the pulmonary artery in an adult; a review of the therapeutic problem. Circulation 33: 727, 1966

8. Pinsky WW, Fagan LR, Gerard MJF, Willman VL: Subclavian-coronary artery anastomosis in infancy for the Bland-White-Garland syndrome; a three year and five year follow-up. J Thorac Cardiovasc Surg 72: 15, 1976

9. Suzuki $Y$, Horiuchi $T$, Ishizawa E, Sato T, Fukuda M, Kakihata H: Subclavian-coronary artery anastomosis in infancy for the Bland-White-Garland syndrome; a two-year angiographic follow-up. Ann Thorac Surg 25: 377, 1978

10. Paridon SM, Farooki ZQ, Kuhs LR, Arciniegas E, Pinsky WW: Exercise performance after repair of anomalous origin of the left coronary artery from the pulmonary artery. Circulation 81: 1287, 1990

11. Yoran C, Yellin EL, Becker RM, Gabbay S, Frater RWM, Sonnenblick EH: Dynamic aspects of acute mitral regurgitation; effects of ventricular volume, pressure and contractility on the effective regurgitant orifice area. Circulation 60: 170, 1979 